\title{
Accuracy of Alvarado Scoring System and Selective Computed Tomography in Diagnosis of Suspected Cases of Acute Appendicitis
}

\author{
Abbas AR Mohamed ${ }^{1 *}$, Safaa A Mobarki ${ }^{2}$, Ashwag H Al Qabasani ${ }^{2}$, Alaa A El Sayed ${ }^{2}$ and Nusiba A Al Shingiti ${ }^{2}$ \\ ${ }^{1}$ Consultant General and Laparoscopic Surgeon, Head of General Surgery Department, NGH -Madinah -KSA. \\ ${ }^{2}$ Surgical Resident, Department of Surgical Specialties, NGH -Madinah -KSA \\ *Corresponding author: Abbas AR Mohamed, Consultant General and Laparoscopic Surgeon, Head of General Surgery Department, NGH - \\ Madinah-KSA.
}

Received date: March 09, 2020; Accepted date: March 17, 2020; Published date: March 20, 2020

Citation: Abbas AR Mohamed, Safaa A Mobarki, Ashwag H Al Qabasani, Alaa A El Sayed and Nusiba A Al Shingiti (2020) Accuracy of Alvarado Scoring System and Selective Computed Tomography in Diagnosis of Suspected Cases of Acute Appendicitis. J Clinical Research and Reports, 1(2); DOI: $10.31579 / 2690-8816 / 015$

Copyright: () 2020 Abbas AR Mohamed. This is an open access article distributed under the Creative Commons Attribution License, which permits unrestricted use, distribution, and reproduction in any medium, provided the original work is properly cited.

\section{Abstract}

Objective: To evaluate the diagnostic accuracy of combined Alvarado scoring system and selective computed tomography (CT) in the diagnosis of suspected cases of acute appendicitis.

Material and methods: This study was conducted during the period March 2018 to January 2020 at Prince Mohammed bin Abdul-Aziz hospital (NGHA) in Al Madinah, KSA. It is a prospective study involving 100 consecutive patients attending the emergency department with right iliac fossa pain, excluding children below the age of 14 years and pregnant women. All patients were initially assessed by the Alvarado scoring system, and the result of each patient was recorded in a separate predesigned data sheath. Based on the patient's calculated Alvarado scores, patients were stratified into three groups: Group A (score $\leq 4)$, Group B (score 5-6), and group C (score $\geq 7$ ). All patients in group A were discharged from the emergency department with instruction to return if their symptoms persist or get worse while all patients in group B had an abdominal multidetector CT scan (MDCT) with IV contrast and no oral contrast to help the diagnosis. Group $\mathrm{C}$ patients had surgery without further investigation. Alvarado scores were compared to intraoperative findings and histopathological examination of the removed appendix in those who were operated. The sensitivity, specificity, positive and negative predictive values of the scoring system in each group were calculated with special reference to the role of CT scan in improving the diagnostic accuracy of the scoring system in the middle group (group B).

Result: 58 patients were male and 42 were female. Age range between 14 and 43 years with median age 24 years. Out of the 100 patients, 14 ( 8 males, 6 females) belonged to Group A, 23 (11 males, 12 females) to Group B and 63 (39 males, 24 females) to group C.

Two patients from group A (one male and one female) were returned with worsening symptoms and subsequently operated for acute appendicitis. CT scan established the diagnosis of acute appendicitis in 16 out of the patients of group B with subsequent histological confirmation of acute appendicitis in 15 of them. Histopathology confirmed the diagnosis of acute appendicitis in 32 out of 63 patients of group C.

Conclusion: Alvarado score has a high accuracy of ruling in and out acute appendicitis at the extremes of the score ( $\leq 7$ and $\geq 4)$, however, the accuracy of the score to confirm or rule out acute appendicitis in the middle group (5 -6) is significantly low. Selective utilization of CT scan in patients in the middle of the score improves the diagnostic accuracy of the score and limits overutilization of CT scan in the other patients at the extremes of the score saving patients unnecessary exposure to radiation and health authorities' time and cost without increasing the rate of negative appendectomy.

Keywords: alvarado scoring; appendicitis; CT scan

\section{Introduction:}

Acute appendicitis remained the most common of acute abdomen since Reginald H Filz, first described the disease and introduced the term appendicitis in 1886 (1)

Typical cases of acute appendicitis usually present with migrating pain start in the para-umbilical region and then localized to the right iliac fossa, associated with nausea, vomiting, low-grade fever, and leukocytosis. Typical cases of acute appendicitis are easy to diagnose and treat, however, atypical presentation is common, occurring in about $20-33 \%$ of cases (2).

Atypical presentations result from many factors including variation in the anatomical position of the appendix, extremes of age, and female sex during childbearing age. The diagnosis of atypical appendicitis is difficult and remains a clinical challenge for even experienced surgeons (3). Studies showed that the accuracy of the clinical diagnosis of acute appendicitis is correlating with the 57 surgeon's experience and ranging between $76 \%$ and $92 \%$, with values (4). 
Despite recent advances in radiological imaging techniques, the diagnosis of appendicitis is still a clinical diagnosis based primarily on taking a proper medical history and conduct proper physical examination (5).

Accuracy of diagnosis of acute appendicitis entitles reaching an early and accurate diagnosis, without increasing the rate of negative appendectomies or perforation.

Misdiagnosis or delay in diagnosis of cases of acute appendicitis associated with serious complications and morbidities, on the other hand, Precaution appendectomy or negative appendectomy is an adverse outcome.

There general tendency of overdiagnosis of the condition to avoid complications related to delayed diagnosis or treatment resulted in a high rate of negative appendectomy.

The old dictums, "When in doubt, take it out" and "it is better to remove a hundred normal appendices than to leave an inflamed one" is no more valid. Negative appendectomies have an adverse effect as it leads to unnecessary surgery $(3,6)$, serious interruption of patient's daily activities and a considerable waste of hospital resources $(3,7)$ in addition to the postoperative complications.

It was estimated that misdiagnosis occurs $20 \%$ of cases of appendicitis; however, negative appendectomy is found in $(15-35 \%)$ of patients who were emergency operated for acute appendicitis (8-10).

Over the years various clinical scoring systems have been used to improve the diagnostic accuracy of acute appendicitis. Although many clinical scoring systems have been developed (11-15), the Alvarado scoring system is the most famous. The scoring system was devised in 1986 by the American surgeon Alfredo Alvarado who identified eight predictive factors to stratify risk of acute appendicitis in his single-center study involving 305 patients in Philadelphia (11).

Alvarado score is a 10-point scoring system, based on three signs, three symptoms, and one investigation. The scoring system classifies patients into three groups based on their scores. Low risk (unlikely to have acute appendicitis with score $\leq 4$ ), Intermediate risk (have a possible diagnosis of acute appendicitis with score 4-5) and high risk (probably having acute appendicitis with score $\geq 7$ ).

The high sensitivity and specificity of computed tomography (CT) in the diagnosis of acute appendicitis were well documented by many researchers. At present, CT plays an important role in the clinical decision-making process in acute appendicitis and is considered as the gold standard in the diagnostic work-up for suspected acute appendicitis (16-19).

In spite of the documented high sensitivity and specificity of CT scan in diagnosis of acute appendicitis and its considerable ability to reduce the level of negative appendectomy, some studies have shown that the use of CT does not necessarily change the clinical management of a patient, especially in those at high risk $(20,21)$. CT imaging may also delay the time of operation and, therefore, may increase the subsequent risk of perforation (22), expose patients to potentially harmful radiation (23), and possibly adds to the overall cost of the emergency department visit (24) in addition to the risk of ionizing radiation.

Increasing reliance and overutilization of (CT) imaging for the diagnosis of acute appendicitis should be discouraged especially in the developing world as it constitutes wasting of resources that should be reserved only for patients whose diagnoses remain uncertain.
Our study aims to evaluate the role of selective CT scan in improving the diagnostic accuracy of the Alvarado scoring system and hence suggest a clinical pathway for patients presenting with clinical features suggestive of acute appendicitis aiming to ensure high diagnostic accuracy without overutilization of CT scan as a diagnostic tool.

\section{Materials and methods:}

A prospective study of 100 consecutive patients who presented to the emergency department at Prince Mohammed bin Abdul-Aziz hospital NGHA in Al Madinah, KSA with the complaint of right iliac fossa pain, in the period from first of March 2018 to 30th of January 2020 excluding patients below the age of 14 years and pregnant females. Patients were assessed initially by detailed history, clinical examination, and basic laboratory tests including urine analysis, full blood count, urea and electrolytes, and coagulation profile. Alvarado score was calculated for each patient and recorded in a predesigned data sheath (Figure 1). Based on the calculated Alvarado scores, patients were stratified into three groups: Group A (Alvarado score $\leq 4$ ) Group B (Alvarado score 5-6) and group $\mathrm{C}$ (Alvarado score $\geq 7$ ).

Patients scored $\leq 4$ were considered very unlikely to have acute appendicitis and were discharged from the emergency department with instruction to come back if their symptoms persist or become worse. Patients scored 5-6 were considered to have a diagnosis compatible with acute appendicitis, but not convincing enough to warrant appendectomy, they all had an abdominal MDCT scan and decisions were taken on the CT scan findings. Patients scored $\geq 7$ were considered to have acute appendicitis and were submitted to operation without further investigations.

The abdomen CT scans were done by the multidetector scanner with IV contrast and no oral contrast. The criteria for positive CT scan were, appendix diameter $>6 \mathrm{~mm}$, appendix thickening $>3 \mathrm{~mm}$ with wall enhancement, caecal and periappendiceal inflammatory changes.

The Alvarado scores were correlated with the CT scan, operative findings and the histopathology of the removed appendices of all patients who were operated for acute appendicitis. The sensitivity, specificity, positive and negative predictive values of the scoring system in each group were calculated with special reference to the role of CT scan in improving the diagnostic accuracy of the scoring system in the middle group. The collected data were analyzed using the $2 \times 2$ table with the calculation of the different variables using the following equations (table 1).

- $\quad$ Sensitivity $(\mathrm{SN})$

○ $\%$ with disease who test positive.

○ True Positive / True Positive False Negative.

- $\quad$ Specificity (SP)

○ \% without disease who test negative

○ True Negative (False Positive True Negative.

- $\quad$ Positive predictive value (PPV)

○ $\%$ positive test results that are true positives

○ True Positive / True Positive +False Positive.

- $\quad$ Negative predictive value (NPV)

$\circ \%$ negative test results that are true negatives

- $\quad$ True Negative / False Negative + True Negative.

- The sensitivity, specificity, positive and negative predictive values of the scores were calculated at two cut points, cut off point of 5 (assuming all patients scored 5-7 were positive) and cut off point of 7 (assuming all patient scored between 5-7 were negative). 
+

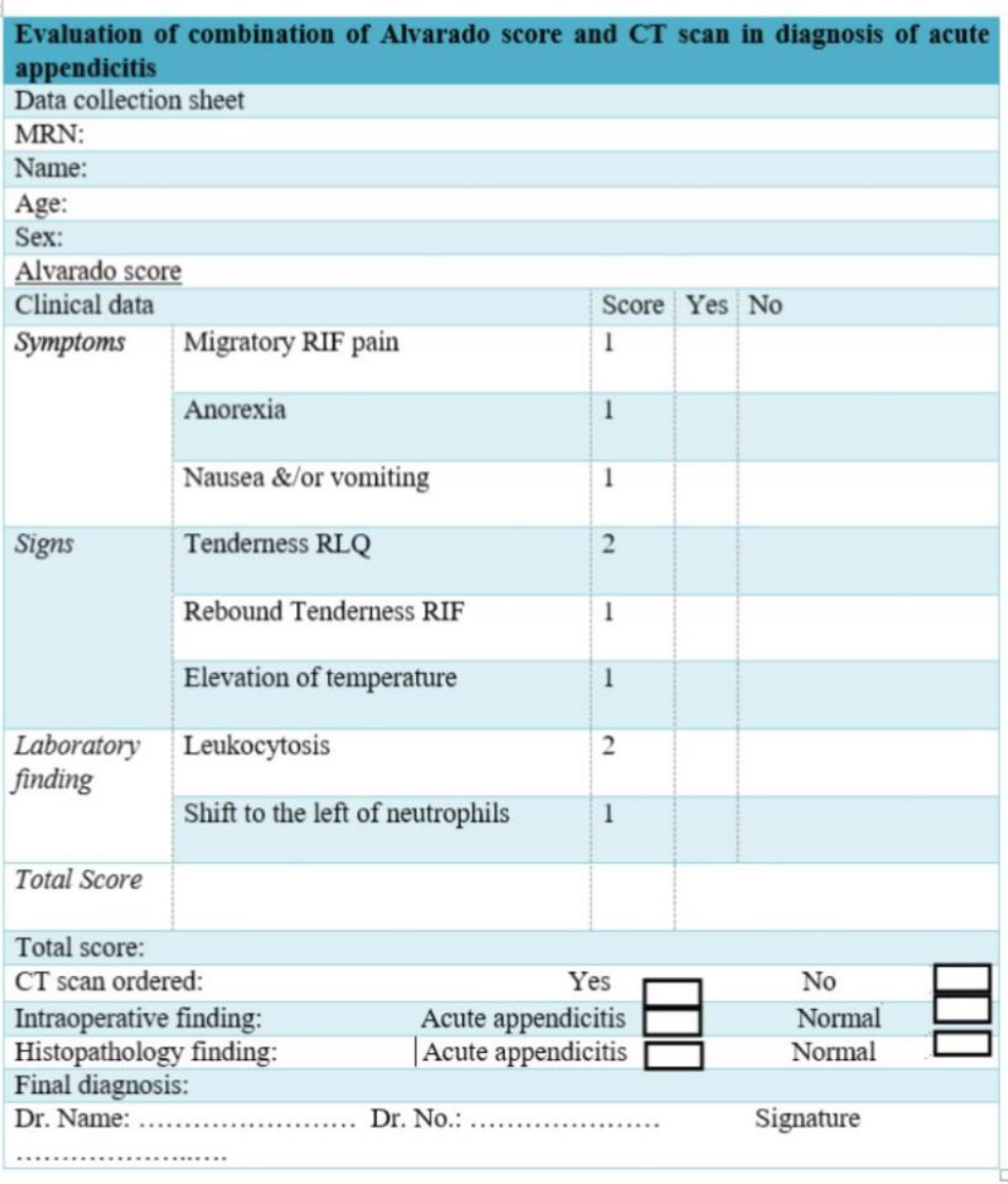

Figure 1: Showing the predesigned data sheath including Patient demographics, Alvarado score, CT scan, intraoperative and histological findings.

\section{Results:}

Among the 100 patients 58 were male (58\%) and 42 were female (42\%). The female to male ratio was 1:1.38 (Table 1, Diagram1). Age range between 14-43 years with Mean age was 24 years (Table 2, Diagram 2).

\begin{tabular}{|l|c|}
\hline Sex & Number \\
\hline Male & 58 \\
\hline Female & 42 \\
\hline Total & 100 \\
\hline
\end{tabular}

Table 2: Sex distribution. 


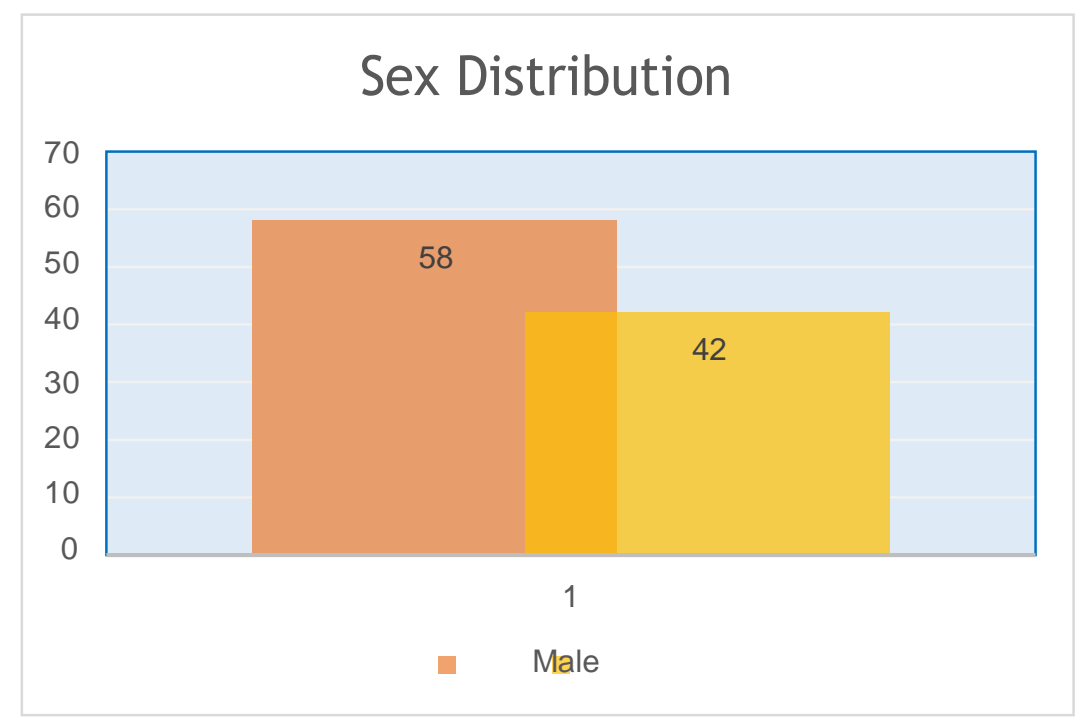

Diagram1: Sex distribution.

\begin{tabular}{|l|l|}
\hline Age / Years & No of patients \\
\hline $\mathbf{1 4 - 1 9}$ & 28 \\
\hline $\mathbf{2 0 - 2 9}$ & 54 \\
\hline $\mathbf{3 0 - 3 9}$ & 16 \\
\hline $\mathbf{4 0 - 4 9}$ & 2 \\
\hline
\end{tabular}

Table 2: Age distribution.

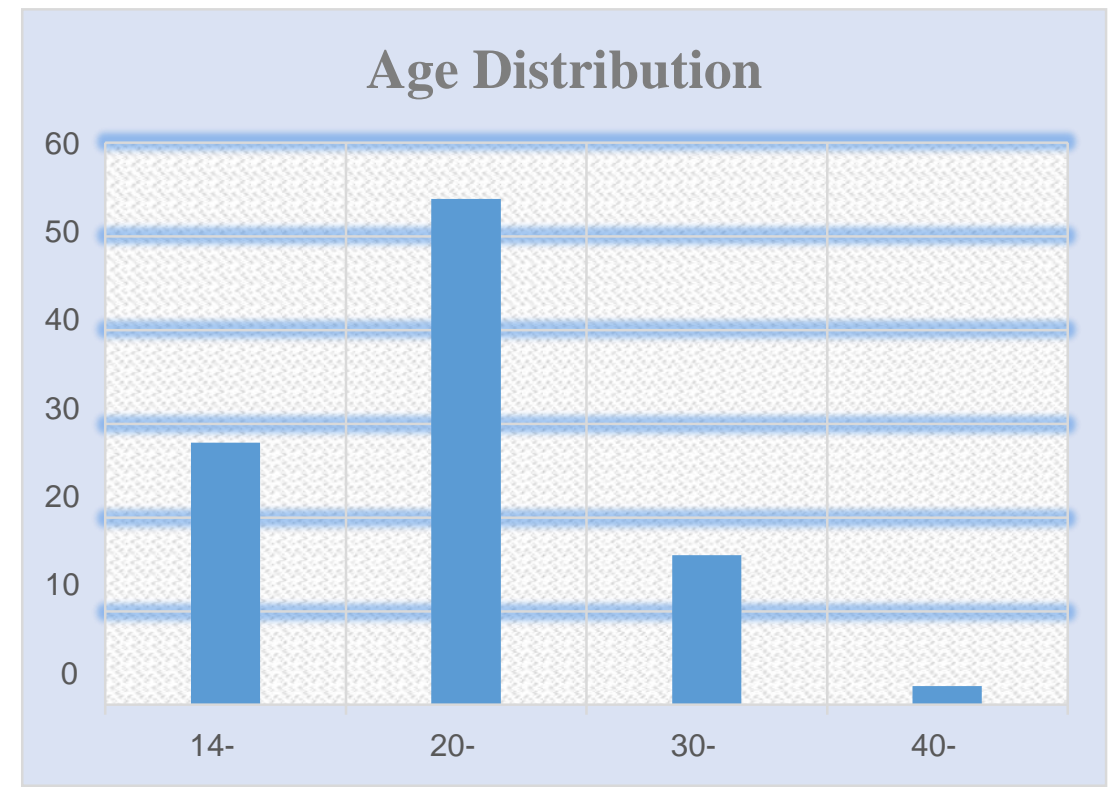

Diagram2: Age distribution. 
Patient's distribution according to scoring system is shown in (Table 3, Diagram 3). In group A we had 14 patients (8 males and 6 females), group B 23 patients (11 males and 12 females) and group C 63 patients (39 males and 24 females).

\begin{tabular}{|l|l|l|l|}
\hline Score & Male & Female & Total \\
\hline Alvarado score $\leq 4$ & 8 & 6 & 14 \\
\hline Alvarado score 5-6 & 11 & 12 & 23 \\
\hline Alvarado score $\geq 7$ & 39 & 24 & 63 \\
\hline Total & 58 & 42 & 100 \\
\hline
\end{tabular}

\section{Patients Distribution Acording to the Scores}

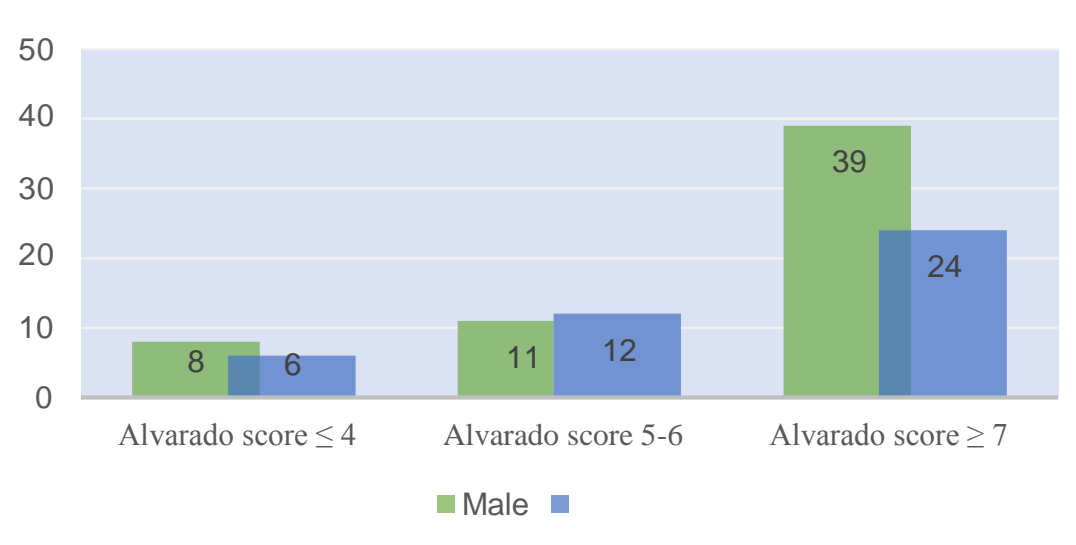

Diagram 3: Patients distribution according to their scores stratified by the sex.

All patients in group A were discharged from the emergency department with instruction to return if their symptoms persist or get worse with only two patients (one male and one female) returned and subsequently operated for acute appendicitis. Each patient in group B had an abdominal MDCT scan which established the diagnosis of acute appendicitis in 16 patients (9 males and 7 females). On laparoscopic exploration one (male patient) was found to have torsion of epiploic appendicitis of the caecum bringing the number of the true positive to 15 with one false-positive result. The intraoperative findings and histopathological examination of the removed appendices confirmed the diagnosis of acute appendicitis in the 15 patients. The CT scan excluded acute appendicitis in the remaining
7 patients of this group who on followed up were found to have other pathologies rather than acute appendicitis. All patients of group $\mathrm{C}$ had appendectomy without further investigations. The histopathology of the removed appendices confirmed the diagnosis of acute appendicitis in 59 patients with 4 negative appendectomies ( 3 females and one male).

The overall diagnostic accuracy or discrimination performance of Alvarado score to rule out acute appendicitis in Group A and to rule in acute appendicitis in Group B and C was calculated and found to be $85.7 \%$ in Group A, 65\% in Group B and 93.6\% in Group C (Table 4, Diagram 4).

\section{Discrimination performance}

$85.7 \%$
$65 \%$
$93.6 \%$




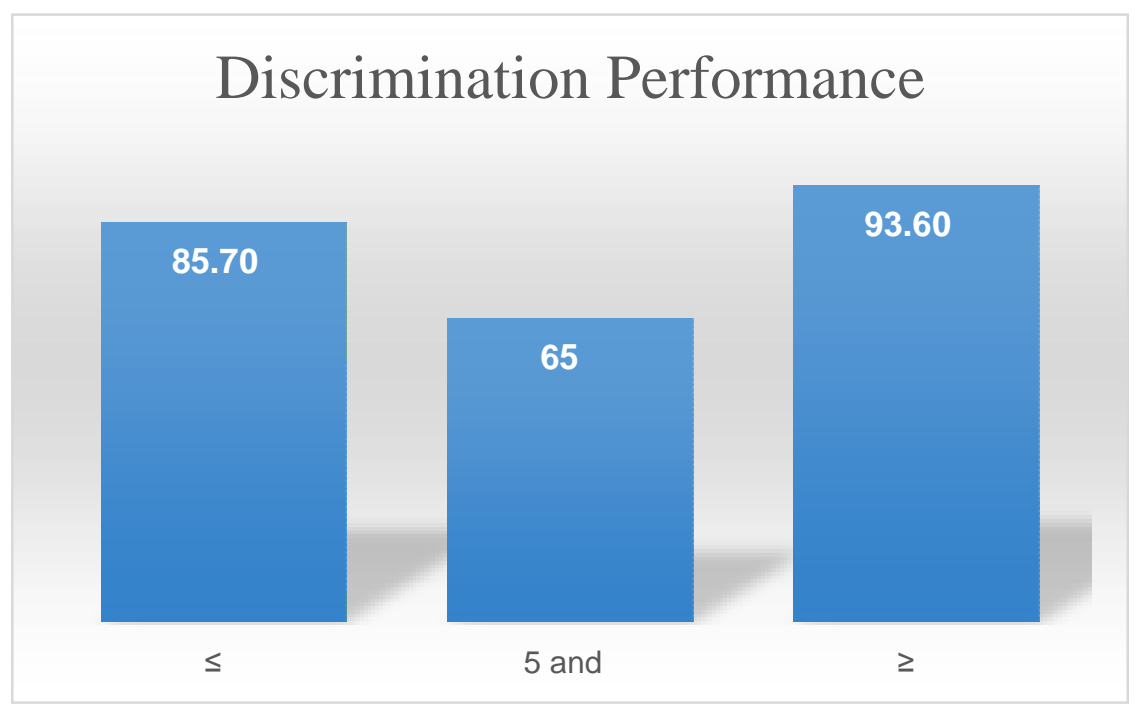

Diagram 4: Accuracy of Alvarado score in each group

The diagnostic accuracy of Alvarado score stratified by sex was found to be (males $87.5 \%$ / females $83 \%$ ) in Group A, (males $72 \%$ / females $58 \%$ ) in Group B and (males 97.4\% / females 87.5) in Group C. (Table 5,Diagram 5).

\begin{tabular}{|lcc|}
\hline Score & Male & Female \\
\hline Alvarado score $\leq 4$ & $87.5 \%$ & $83 \%$ \\
\hline Alvarado score 5-6 & $72 \%$ & $58 \%$ \\
\hline Alvarado score $\geq 7$ & $97.3 \%$ & 87.5 \\
\hline
\end{tabular}

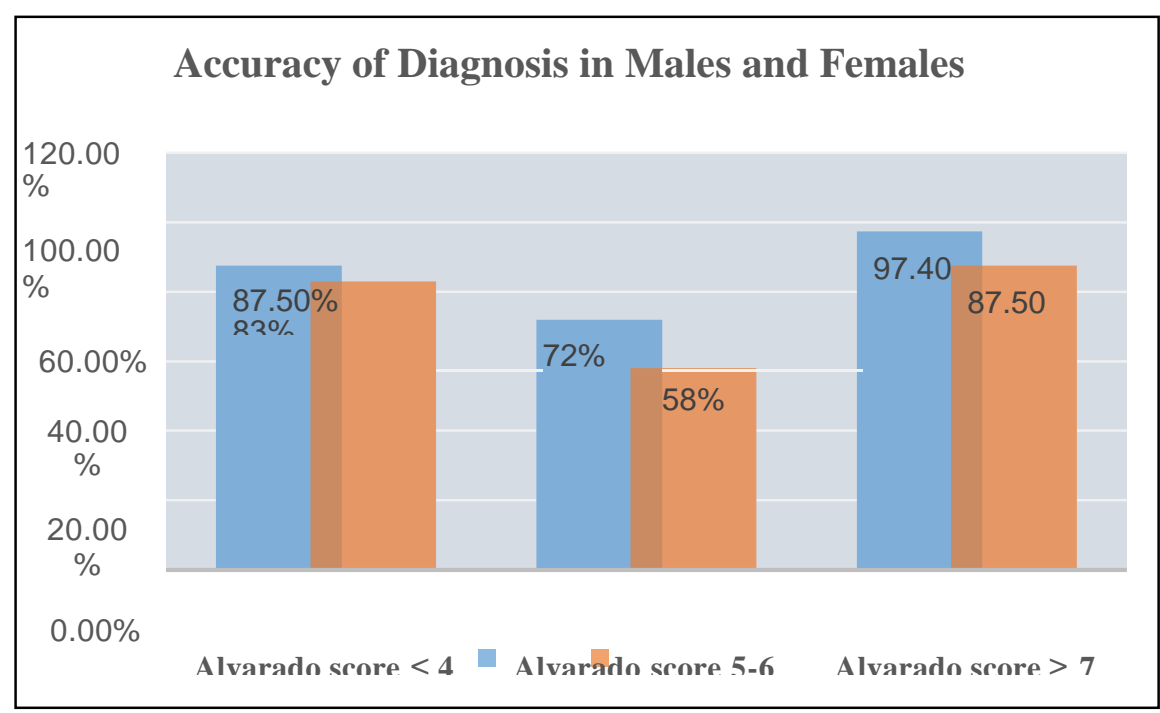

Diagram 5: Accuracy of Alvarado score stratified by sex 
The calculated sensitivity, specificity, PPV, and NPV of $77.6 \%, 83.3 \%, 93.7 \%$ and $54 \%$ respectively at cut off point $\geq 7$ and $97.3 \%, 50 \%, 86 \%$ and $85.7 \%$ respectively at cut off point $\leq 4$ (Table 6 , Diagram 6 ).

\begin{tabular}{|c|c|c|c|c|}
\hline $\begin{array}{l}\text { Cut off point / } \\
\text { variables }\end{array}$ & Sensitivity & Specificity & $P P V$ & $N P V$ \\
\hline $\begin{array}{l}\text { Cut off point } \geq \\
7\end{array}$ & $77.6 \%$ & $83.3 \%$ & $93.6 \%$ & $54 \%$ \\
\hline $\begin{array}{l}\text { Cut off point } \leq \\
4\end{array}$ & $97.3 \%$ & $50 \%$ & $86 \%$ & $85.7 \%$ \\
\hline
\end{tabular}

Table 6: Alvarado score performance at cut off point $\geq 7$ and $\leq 4$.

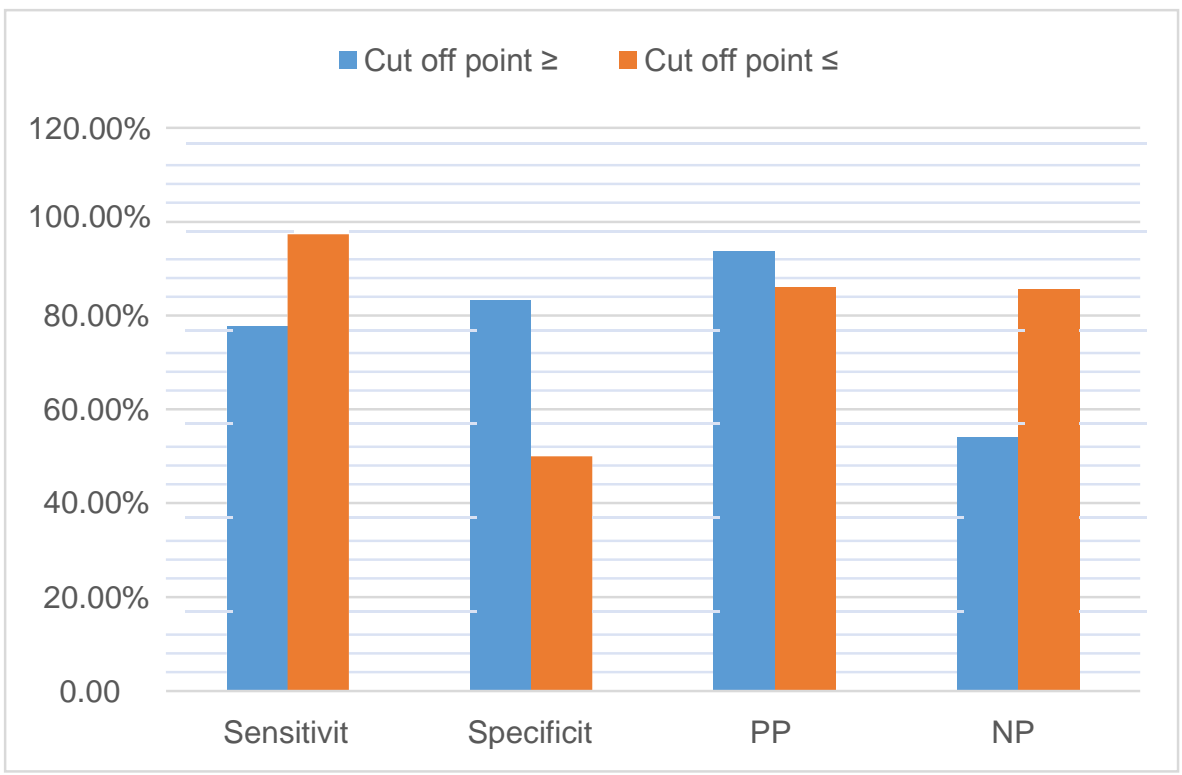

Diagram 6: Alvarado score performance at cut off point $\geq 7$ and $\leq 4$.

The calculated discrimination performance of the score with CT revealed sensitivity, specificity, PPV and NPV at cut off point $\geq 7$ were $97.3 \%, 79.2 \%$, $93.6 \%$, and $90.4 \%$ respectively in comparison to the calculated discrimination performance of the score without CT of $77.6 \%, 83.3 \%, 93.7 \%$ and $54 \%$ respectively (Table 7, Diagram7).

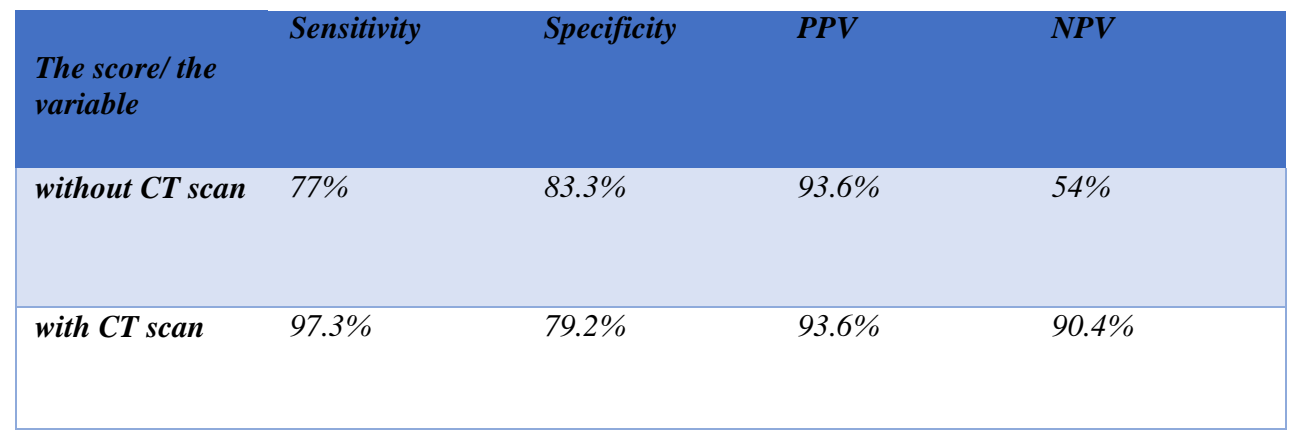

Table 7: Comparison of the performance of Alvarado score with and without CT scan. 


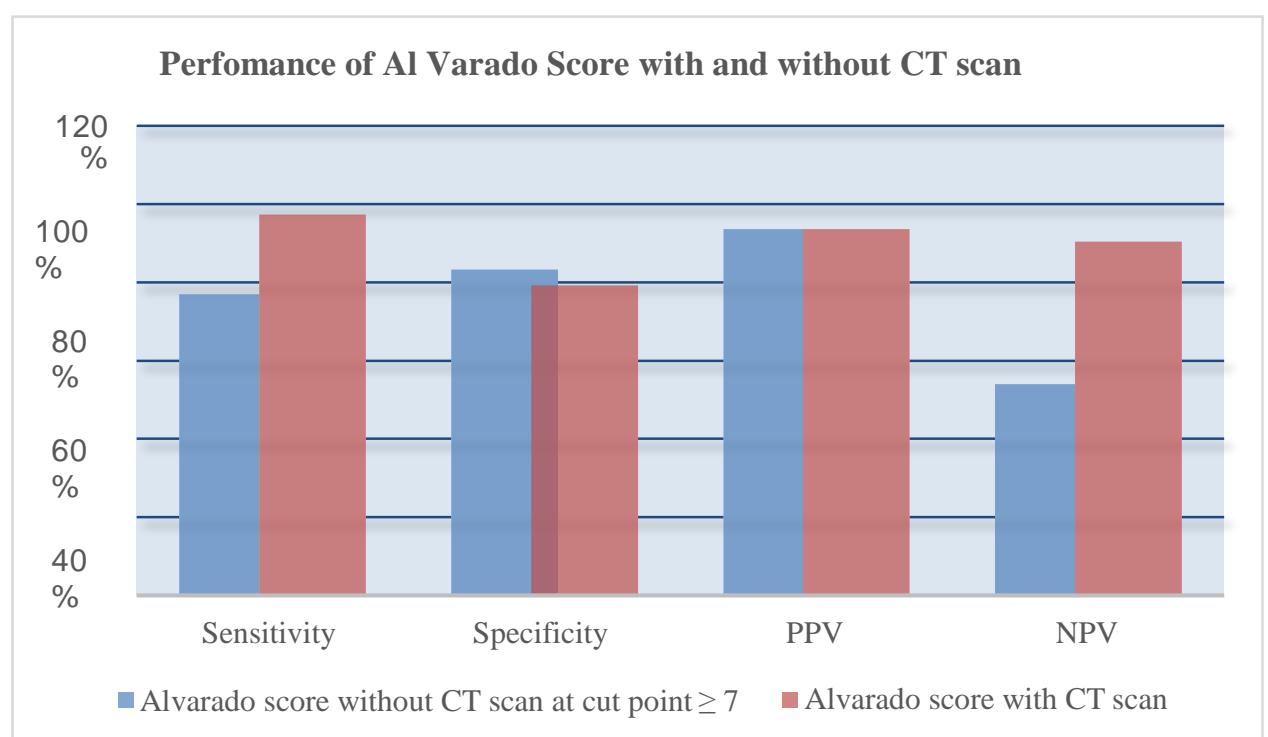

Diagram7: Comparison of the performance of Alvarado score with and without CT scan.

\section{Discussion:}

Acute appendicitis is the most common surgical emergency seen in most hospitals throughout the world and the most common cause of acute abdomen requiring surgical intervention. Appendectomy remained the most commonly performed emergency surgical procedure since the first appendectomy was performed by Treves in England (25).

The incidence of acute appendicitis and male and female distribution varies from one population to another. The estimated lifetime risk is $8.6 \%$ for males and $6.7 \%$ for females in the United States (26). Addis's DG et al, (26) in their analysis of the epidemiology of appendicitis and appendectomy in the United States reported slight female to male predominance (1:1.3). A similar female to male ratio of $1: 1.4$ was reported by Omran, $\mathrm{M}$ et al, (27) in their study of the epidemiologic features of acute appendicitis in Ontario, Canada.

Körner H, et al,(28) in their Age-specific and Sex-specific Analysis of the incidence of Acute no perforated and perforated appendicitis, in 1486 Scandinavian patients reported male to female predominance. Similarly, Ceresoli M, et al, (29) in their retrospective cohort study derived from the administrative dataset of the Bergamo district healthcare system in Italy which involved 16544 consecutive cases of acute appendicitis, reported incidence of $54.7 \%$ in males versus $45.3 \%$ in females with female to male ratio of 1.2:1. Our study showed a comparable sex distribution with an incidence of $(58 \%)$ in males and $(42 \%)$ in females with female to male ratio of 1:1.38 (table1), however, this may not presents the true incidence of the disease in the population because of the exclusion criteria.

Acute appendicitis is most common in the western population at the age $(10-20)$ years but no age is exempt $(26,30)$. Our study showed a higher incidence of acute appendicitis in the age group 20-29 (54\%) which represents the incidence in the adult population. A similar age incidence was reported in many studies that excluded children from the developing world (31-33), however, some studies, reported high incidence in the third decade (34).

Since the Alvarado scoring system was introduced, the accuracy and predictive values of the score in the diagnosis of acute appendicitis were intensively investigated by many researchers with very conflicting results. The accuracy (discrimination performance) of the Alvarado scoring system differs from one study to another and also differs at the different cut off points. Many studies suggested that patients with score $\leq 4$ can be safely discharged home, those with scores 5-7, are in need of radiological investigations, and those with score $>7$ should be operated without further investigations (35-37)

Our study showed an accuracy of Alvarado score (discrimination performance) in ruling in acute appendicitis of $93.6 \%$ at a cut-off point of $\geq 7$ which is comparable to the accuracy of $93 \%$ reported by Alvarado (11) in the same group of patients and an accuracy in ruling out acute appendicitis at cut off point of $\leq 4$ of $85.7 \%$ comparable to the $85 \%$ reported by McKay Ret, et al (38) at the same cut of point. In the middle group of patients with (Alvarado score 5-6) the accuracy of the score to rule in acute appendicitis was $65 \% \%$.

Our study also showed better performance of Alvarado score in males than in females throughout the scores (table5, diagram5) which was reported in most of the published studies (39-42).

The sensitivity, specificity, PPV, and NPV of Alvarado score varies from one study to another. The wide discrepancy between the different studies is most probably due to variation in the selected cut off points for the negative and positive values. Although there is no agreeable ideal optimum cut-off point for the Alvarado score, most studies consider score $\geq 7$ as an optimum cut off point (43).

Ohle Robert, et al, (42) in their systematic review and meta-analysis of validation studies that assess the Alvarado score in order to determine its performance (diagnostic accuracy at two cut- points commonly used for decision making, and calibration of the score) found that the cut-point of 5 is good at 'ruling out' admission for appendicitis (sensitivity $94 \%$ to $99 \%)$.

The discriminant analysis of Shrivastava UK et al, (44) to determine the cut-off value in an Indian set-up revealed that a cut-off value of $\geq 6$ rather than the original value of $\geq 7$ increases the sensitivity of the Alvarado score from $69.2 \%$ to $92 \%$.

Our study revealed a sensitivity $77.6 \%$, specificity of $83.3 \%$, PPV of $93.7 \%$, and NPV of $54 \%$ respectively at cut off point $\geq 7$ and sensitivity of $97.3 \%$, specificity of $50 \%$, \%, PPV of $86 \%$, and NPV of $85.7 \%$ respectively at cut point $\leq 4$ (Table 6 , Diagram 6) which explains and confirms the differences of those variables at different cuff off points and in the different published studies. 
The calculated sensitivity and specificity at the cut-off point $\geq 7$ in our study ( $77.6 \%$, and $83.3 \% 278$ respectively) were comparable to the result of Ohmann et al, (12) who reported a sensitivity of $64 \%$, and specificity of $84 \%$. It is also comparable to the results of McKay R et al (38) who reported sensitivity for of $77 \%$, and the specificity $100 \%$ at the same cut off point.

Our reported PPV of $93.7 \%$ is comparable to the PPV reported by Özsoy $Z$, et al (43) and Pogorelić et al (45) who reported PPV of $93.7 \%$ and $93.1 \%$ respectively at the same cut off point.

Computed tomography (CT) is considered the gold standard in the diagnosis of acute appendicitis. The impact of CT scan in improving the diagnostic accuracy in patients presenting with clinical symptoms suspicious of appendicitis was widely researched in the literature. Many studies $(46,47)$ documented the high sensitivity and specificity of the (CT) for the diagnosis of acute appendicitis. Some authors reported that the use of CT scan in the diagnosis of acute appendicitis has decreased the rate of negative appendectomy to less than $10 \%(48,49)$.

Krajewski S, et al, (50) in their systematic review of the literature which included 28 full-text articles that examined the clinical outcomes related to the use of abdominal CT in the diagnosis of acute appendicitis reported a significant reduction of the rate of negative appendectomy( from 16.7\% to $8.7 \%$ ) when using CT compared with when using clinical evaluation alone.

Balthazar EJ, et al (51) evaluated the impact of CT on negative appendectomy and perforation rates in patients with the equivocal clinical presentation of acute appendicitis in their retrospective analysis of 146 consecutive patients with suspected acute appendicitis. They reported a negative appendectomy rate of $4 \%$ out of 122 patients who had an appendectomy. Unnecessary surgery was avoided in 24 patients. They concluded that the judicious use of CT imaging in patients suspected with acute appendicitis with equivocal clinical presentation led to a significant improvement in diagnosis and resulted in a decrease in the negative appendectomy rate, without increasing the perforation rate.

in our study, the combination of the Alvarado scoring system and selective CT scan in patients with equivocal clinical presentation (Alvarado score 5-6) resulted in a total of 5 negative appendectomies in 79 patients who were diagnosed to have acute appendicitis with $6.3 \%$ rate of negative appendectomy. Our result is comparable to many studies. The selective use of CT scan also saved 7 patients with an equivocal presentation from having unnecessary surgery.

McKay R, et al (38) in their retrospective review of 150 charts of patients who presented with abdominal pain documented that CT scan improves the sensitivity Alvarado scoring system in patients with an equivocal clinical presentation of appendicitis (defined by Alvarado scores of 4 to 6) from $35.6 \%$ to $90.4 \%$. They concluded that CT scan is beneficial in patients with equivocal scores. Our study showed similar improvement of Alvarado scores by CT scan in patients with an equivocal clinical presentation of appendicitis (score 5-6) with an improvement of the PPV of the scoring system from $65 \%$ to $93.7 \%$.

The calculated sensitivity, specificity, PPV and NPV of CT scan in our study were $100 \%, 87.5 \%, 93.7 \%$ and $100 \%$ respectively which is comparable to the reported values in many studies that reported sensitivity of $90-100 \%$, specificity of $91-99 \%$, accuracies of $94-98 \%$, positive predictive values (PPVs) of 92-98\%, and negative predictive values (NPVs) of 95-100\% for diagnosing acute appendicitis $(18,52-54)$.

The overall discrimination performance of the Alvarado score and the selective CT scan in the consecutive 100 patients who presented with right iliac fossa pain of our study resulted in a total of 74 patient correctly diagnosed to have acute appendicitis who were proved to be positive both by intraoperative findings and histopathology (true positives). Negative appendectomy was performed in 5 patients ( 5 false positives) and 2 patient was diagnosed not to have acute appendicitis who were subsequently operated for acute appendicitis (false negative). Acute appendicitis was correctly excluded in 19 patients (true negatives), 7 patients were saved from unnecessary surgery and 77 patients were save from having unnecessary CT scan. The calculated sensitivity, specificity, PPV and NPV of Alvarado scoring system and selective CT scan at cut off point $\geq 7$ were $97.3 \%, 79.2 \%, 93.6 \%$, and $90.4 \%$ respectively in comparison to $77.6 \%, 83.3 \%, 93.6 \%$, and $54 \%$ respectively of Alvarado scoring system without CT scan at the same cut off point, with significant improvement in the sensitivity, and the NPV without significant change of the specificity and the PPV of the score (Table 7, Diagram7).

Our clinical pathway resulted in 5 negative appendectomies, 7 patients were saved from having a negative appendectomy, and 77 patients were save from having unnecessary CT scan with its potential risk, and health authority was saved considerable time and cost. As most cases of suspected acute appendicitis are dealt with by junior surgical staff in most hospitals throughout the world, lacks an efficient clinical pathway to guide junior staff in decision making in diagnosis and management of those cases resulted in over diagnosis, namely ultrasound and CT scan. We highly recommend adopting similarly efficient clinical pathways in emergency departments set up for the diagnosis of suspected cases of acute appendicitis especially in developing countries with limited facilities and resources.

\section{Conclusion:}

Since the Alvarado scoring system was introduced, the accuracy and predictive values of the score in the diagnosis of acute appendicitis was intensively investigated by many researchers with conflicting results. Alvarado score has a high accuracy of ruling in and out acute appendicitis at the extremes of the score $(\leq 7$ and $\geq 4)$ however the accuracy of the score at the middle group (5-6) is significantly low. Although CT scan is proved to have high sensitivity and specificity in the diagnosis of acute appendicitis, CT imaging may delay the time of operation increases the risk of perforation in addition to its cost and potentially harmful radiation.

Increasing reliance and overutilization of CT scan imaging for the diagnosis of acute appendicitis should be discouraged especially in the developing world as it constitutes wasting of resources that should be reserved only for patients whose diagnoses remain uncertain.

A combination of Alvarado scoring system and selective CT limited to the patients with equivocal clinical presentation (score 5-6) improves the diagnostic accuracy of the Alvarado scoring system and limits overutilization of $\mathrm{CT}$ scan saving patients unnecessary exposure to radiation and health authorities' time and cost.

We highly recommend adopting similarly efficient clinical pathways in emergency departments set up for the diagnosis of suspected cases of acute appendicitis especially in developing countries with limited facilities and resources.

\section{Conflict of Interest: None declared}

\section{References:}

1. Fitz RH: (1886). Postoperative inflammation of vermiform appendix with special reference to its easy diagnosis and treatment. AMJ Medication Sci; 92:321-3462.

2. Lane MJ. (1997). Unenhanced helical CT for suspected acute appendicitis. Am J Roentgenol; 168:405-9. 
3. A Mohamed, N Bhat. (2009). Acute Appendicitis Dilemma of Diagnosis and Management. The Internet Journal of Surgery. Volume 23 Number 2.

4. Shakhatreh HS: (2000). The accuracy of C-reactive protein in the diagnosis of acute appendicitis compared with that of clinical diagnosis. Med Arh; 54:109-10.

5. Hardin DM Jr: (1999). Acute appendicitis: review and update. Am Fam Physician; 60(7):2027-2034.

6. Flum DR, Morris A, Koepsell T, Dellinger EP. (2001). Has misdiagnosis of appendicitis decreased over time? JAMA; 286:1748-1753.

7. Jones PF: (2001). Suspected acute appendicitis. Trend in management over 30 years. Br J Surg; 88:1570-7.

8. Koch A, Marusch F, Schmidt U, Gastinger I, Lippert H: (2002). Appendicitis in the last decade of the $20^{\text {th }}$ century. Zentralbl Chir; 127:290-6.

9. Bisard D, Rosenfield JC, Estrada F, Reed JF: (2003). Institutioning a clinical guideline practice to decrease the rate of normal appendectomies. Am Surg; 69:796-8.

10. Rettenbacher T, Hollerweger A, Greitzmann N, Gotwald T, Schwamberger K, et al. (2002). Appendicitis: Should diagnostic imaging be performed if the clinical presentation is highly suggestive of the disease. Gastroenterology; 123:992-8.

11. A. Alvarado. (1986). A practical score for the early diagnosis of acute appendicitis. Ann Emerg Med, 12, pp. 557-564.

12. C. Ohmann, Q. Yang, C. Franke. (1995). Diagnostic scores for acute appendicitis. Abdominal Pain Study Group Eur J Surg, 161, pp. 273-281.

13. W.T. van den Broek, B.B. Bijnen, B. Rijbroek, et al. (2002). Scoring and diagnostic laparoscopy for suspected appendicitis Eur J Surg, 168, pp. 349-354.

14. G. Fenyo, G. Lindberg, P. Blind, et al. (1997). Diagnostic decision support in suspected acute appendicitis: validation of a simplified scoring system Eur J Surg, 163, pp. 831-838.

15. F. Christian, G.P. Christian. (1992). A simple scoring system to reduce the negative appendectomy rate Ann R Coll Surg Engl, 74, pp. 281-285.

16. S. S. Raman, D. S. K. Lu, B. M. Kadell, D. J. Vodopich, J. Sayre, et al. (2002). "Accuracy of non-focused helical CT for the diagnosis of acute appendicitis: a 5-year review," American Journal of Roentgenology, vol. 178, no. 6, pp. 1319-1325.

17. D. S. Tsze, L. M. Asnis, R. C. Merchant, S. Amanullah, and J. G. Linakis. "Increasing computed tomography use for patients with appendicitis and discrepancies in pain management between adults and children: an analysis of the NHAMCS," Annals of Emergency Medicine, vol. 59, no. 5, pp. 395-403, 2012.

18. K. Cağlayan, Y. Günerhan, A. Koç, M. A. Uzun, E. Altinli, et al. (2010). "The role of computerized tomography in the diagnosis of acute appendicitis in patients with negative ultrasonography findings and a low Alvarado score," Ulusal Travma ve Acil Cerrahi Dergisi, vol. 16, no. 5, pp. 445-448.

19. J. Debnath, R. Kumar, A. Mathur et al. (2015). "On the role of ultrasonography and CT scan in the diagnosis of acute appendicitis," Indian Journal of Surgery, vol. 77, supplement 2, pp. 221-226.

20. Petrosyan M, Estrada J, Chan S, Somers S, Yacoub WN, et al. (2008). CT scan in patients with suspected appendicitis: clinical implications for the acute care surgeon. Eur Surg Res., 40: 211-219.

21. Santos DA, Manunga J Jr, Hohman D, Avik E, Taylor EW. (2009). How often does computed tomography change the management of acute appendicitis? Am Surg. 75(10):918-921.
Karakas SP, Guelfguat M, Leonidas JC, Springer S, Singh SP: (2000). Acute appendicitis in children: comparison of clinical diagnosis with ultrasound and CT imaging. Pediatr Radiol., 30: 94-98.

23. A. Berrington, de Gonzalez, S. Darby. (2004). Risk of cancer from diagnostic $\mathrm{x}$-rays: estimates for the UK and 14 other countries. Lancet, 363, pp. 345-351.

24. D.B. Safran, D. Pilati, E. Folz, et al. (2001).Is appendiceal CT scan overused for evaluating patients with right lower quadrant pain? Am J Emerg Med, 19, pp. 199-203.

25. Treves F. (1902). The Cavendish lecture on some phases of inflammation of the appendix: Delivered before the West London Medico-Chirurgical Society. Br Med J. 1902; 1:15891594.

26. Addiss DG, Shaffer N, Fowler BS, Tauxe RV. (1990). The epidemiology of appendicitis and appendectomy in the United States. Am J Epidemiol.; 132(5):910-925.

27. Korner H, Sondenaa K, Soreide JA, et al. (1997). Incidence of nonperforated and perforated appendicitis: age-specific and sex-specific analysis. World J Surg.; 21:313-317.

28. Al-Omran, M, Mamdani, M.M., McLeod, R.S. (2003). Epidemiologic features of acute appendicitis in Ontario, Canada. Canadian Journal of Surgery Volume 46, Issue 4, August, Pages 263-268.

29. Ceresoli M, Zucchi A, Allievi N, et al. (2016). Acute appendicitis: Epidemiology, treatment and outcomes- analysis of 16544 consecutive cases. World J Gastrointest Surg.; 8(10):693-699.

30. Humes DJ, Simpson J. (2006). Acute appendicitis. BMJ. Sep 9; 333(7567):530-4

31. Harsha. B Kodliwadamath et al. (2011). In Evaluation of Modified Alvardo Scoring in the diagnosis of acute appendicitis and its correlation with Ultra Sonography and Histopathology. J Clin Biomed Sci:1(4)

32. Gujar N, Mudhol S, Choudhari RK, Sachin DM. (2015). Determination of sensitivity and specificity of modified Alvarado score and ultrasonography in patients with acute appendicitis. JKIMSU.; 4(2):89-99.

33. Mondal HP , Hadiuzzaman M , Mukhopadhyay C , Chattopadhyay S , Biswas SK, et al. Usefulness of Modified Alvarado Score in Diagnosis of Acute Appendicitis in Adults.

34. Talukder DB, Siddiq AKMZ. (2009). Modified Alvarado scoring system in the diagnosis of acute appendicitis. JAFMC Bangladesh; 5(1):18-20.

35. Yildirim E, Karagülle E, Kirbas I, Türk E, Hasdoğan B, et al. (2008). Alvarado scores and pain onset in relation to multislice CT findings in acute appendicitis. Diagn Interv Radiol.; 14:14 18.

36. Denizbasi A, Unluer EE. (2003). The role of the emergency medicine resident using the Alvarado score in the diagnosis of acute appendicitis compared with the general surgery resident. Eur J Emerg Med; 10:296-301.

37. Sooriakumaran P, Lovell D, Brown R. (2005). A comparison of clinical judgment versus the modified Alvarado score in acute appendicitis. Int J Surg; 3:49-52.

38. McKay R, Shepherd J. (2007). The use of the clinical scoring system by Alvarado in the decision to perform computed tomography for acute appendicitis in the ED. Am J Emerg Med.; 25(5):489-493.

39. Kariman et al. (2014). Evaluation of the Alvarado score in acute abdominal pain. Ulus Travma Acil Cerr Derg, , Vol. 20, No. 2. 
40. Sanei B, Mahmoodieh M, Hosseinpour M. (2009). Evaluation of validity of Alvarado scoring system for diagnosis of acute appendicitis. Pak J Med Sci; 25(2):298-301.

41. Mohamed Kamel El-Mezayen, Ali Ragab Mahmoud, Eslam Nouman Shehatah. (2018). "A Comparative Study between Appendicitis Inflammatory Response Score and Alvarado Score in the Diagnosis of Acute Appendicitis". The Egyptian Journal of Hospital Medicine, 73, 8, 7317-7322.

42. Ohle, R., O'Reilly, F., O'Brien, K. K., Fahey, T., and Dimitrov, B. D. (2011). The Alvarado score for predicting acute appendicitis: a systematic review. BMC medicine, 9, 139.

43. Özsoy Z, Yenidoğan E. (2017). Evaluation of the Alvarado scoring system in the management of acute appendicitis. Turk J Surg.; 33(3):200-204.

44. Shrivastava UK, Gupta A, Sharma D. Evaluation of the Alvarado score in the diagnosis of acute appendicitis. Trop Gastroenterology. 2004; 25(4):184-186.

45. Pogorelić Z, Rak S, Mrklić I, Jurić I. Prospective validation of Alvarado score and pediatric appendicitis score for the diagnosis of acute appendicitis in children. Pediatr Emerg Care. 2015; 31:164-168.

46. J.T. Rhea, E.F. Halpern, T. Ptak, et al. (2005). The status of appendiceal $\mathrm{CT}$ in an urban medical center 5 years after its introduction: experience with 753 patients Am J Roentgenol, 184 pp. $1802-1808$.

47. K. Jones, A.A. Pena, E.L. Dunn, et al. (2004). Are negative appendectomies still acceptable? Am J Surg, 188, pp. 748-754
J.J. Hong, S.M. Cohn, A.P. Ekeh, et al. (2003). A prospective randomized study of clinical assessment versus computed tomography for the diagnosis of acute appendicitis. Surg Infect, 4, pp. 231-239.

49. D.S. Smink, J.A. Finkelstein, B. Garcia, M. Pena, et al. (2004). Diagnosis of acute appendicitis in children using a clinical practice guideline. J Pediatr Surg, 39, pp. 458-463.

50. Krajewski S, Brown J, Phang PT, Raval M, Brown CJ. (2011). Impact of computed tomography of the abdomen on clinical outcomes in patients with acute right lower quadrant pain: a meta-analysis. Can J Surg.; 54(1):43-53.

51. Balthazar EJ, Rofsky NM, Zucker R. (1998). Appendicitis: the impact of computed tomography imaging on negative appendectomy and perforation rates. Am J Gastroenterol.; 93(5):768-771.

52. Jo YH, Kim K, Rhee JE, et al. (2010). The accuracy of emergency medicine and surgical residents in the diagnosis of acute appendicitis. Am J Emerg Med; 28(7):766-770.

53. Lee C.C., Golub R., Singer A.J., Cantu R., Jr., Levinson H. (2007). Routine versus selective abdominal computed tomography scan in the evaluation of right lower quadrant pain: a randomized controlled trial. Acad Emerg Med.; 14(February (2)):117-122.

54. Kim K., Kim Y.H., Kim S.Y. (2012). Low-dose abdominal CT for evaluating suspected appendicitis. N Engl J Med; 366(April (17)):1596-1605.

48.

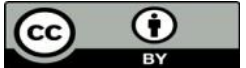

This work is licensed under Creative Commons Attribution 4.0 License

To Submit Your Article Click Here: Submit Manuscript

DOI: $10.31579 / C R N .2020 / 015$
Ready to submit your research? Choose Auctores and benefit from:

* fast, convenient online submission

* rigorous peer review by experienced research in your field

* rapid publication on acceptance

* authors retain copyrights

* unique DOI for all articles

* immediate, unrestricted online access At

Auctores, research is always in progress.

Learn more https://www.auctoresonline.org/journals/clinical-research- notes- 